\title{
QUANTIFICAÇÃO DE COMPOSTOS BIOATIVOS EM DIFERENTES PARTES DO CORPO DA FALSA MURTA Murraya paniculata (L.) Jak
}

\author{
Simony Marques da Silva Gandine ${ }^{1}$ \\ Kamilla Matos Boldrini ${ }^{2}$ \\ Mônica dos Santos Velozo ${ }^{3}$ \\ Luciano Menini $^{4}$ \\ Atanásio Alves do Amaral ${ }^{5}$ \\ Tércio da Silva de Souza ${ }^{6}$
}

Resumo: Uma vez que as plantas medicinais são identificadas e utilizadas em função de seus constituintes químicos, objetivou-se com este estudo, quantificar os teores de fenólicos totais, flavonóis totais e antocianinas presentes na espécie vegetal Murraya paniculata (L.) Jack (murta), correlacionando os teores encontrados nas partes da planta com duas diferentes estações do ano (verão e inverno). As folhas de murta foram coletadas no município de Alegre - ES, dividindo em partes (ápice, mediano e basal), obedecendo às estações verão/inverno. No verão, observaram-se os maiores teores de metabólicos nos ramos medianos, e basal da planta, com exceção dos fenólicos totais que apresentaram os maiores teores no inverno. Com os resultados encontrados, conclui-se que existe uma diferença significativa entre partes da planta e época, e tais resultados estimulam a continuação de estudos com esta espécie.

Palavras-chave: Plantas medicinais; Compostos bioativos; Murta; Sistemas agroecológicos.

\footnotetext{
${ }^{1}$ Licenciatura em Ciências Biológicas/Instituto Federal do Espírito Santo - Campus de Alegre, ES, Brasil. E-mail: marquesgandi@hotmail.com.

${ }^{2}$ Licenciatura em Ciências Biológicas/Instituto Federal do Espírito Santo - Campus de Alegre, ES, Brasil. E-mail: kamillamb1994@gmail.com.

${ }^{3}$ Licenciatura em Ciências Biológicas/Instituto Federal do Espírito Santo - Campus de Alegre, ES, Brasil. E-mail: monicavellozobio@gmail.com.

4 Professor Doutor/Instituto Federal do Espírito Santo - Campus de Alegre, ES, Brasil. E-mail: Imenini@ifes.edu.br.

5 Professor Doutor /Instituto Federal do Espírito Santo - Campus de Alegre, ES, Brasil. E-mail: atanasio@ifes.edu.br.

6 Professor Doutor /Instituto Federal do Espírito Santo - Campus de Alegre, ES, Brasil. E-mail: tssouza@ifes.edu.br.
} 